\title{
Correction: Transcriptomics and proteomics analyses of the PACAP38 influenced ischemic brain in permanent middle cerebral artery occlusion model mice
}

Motohide Hori ${ }^{1,2}$, Tomoya Nakamachi ${ }^{2,4}$, Randeep Rakwal ${ }^{2,4^{*}}$, Junko Shibato ${ }^{2}$, Tetsuo Ogawa ${ }^{2}$, Toshihiro Aiuchi ${ }^{2}$, Tatsuaki Tsuruyama ${ }^{1}$, Keiji Tamaki ${ }^{1}$ and Seiji Shioda ${ }^{2 *}$

The Figure Two (Figure 1 here), $\mathrm{X}$-axis description of each sample was inverted in the original publication [1].

With reference to corrected Figure Two (Figure 1 here), we have the following revised text.

On Page 9, left column: lines 19-24 should read as -

"Similarly, Il6, S100a5, Il22, Il1b, Igf1, and Ccl2 were highly expressed at $6 \mathrm{~h}$ in the PACAP-treated ischemic brain, whereas their expression level decreased at $24 \mathrm{~h}$ compared to the PMCAO effect alone (Figure Two (Figure 1 here)). Fgf21, Pitpnc1, and Epha3 genes showed an increase in expression at $24 \mathrm{~h}$ over PMCAO alone (Figure Two (Figure 1 here))."

On Page 11, right column: lines 16-19 should read as -

"In the ischemic hemisphere at $24 \mathrm{~h}$, the PACAP plus PMCAO expression level of $I l 6$ was also reduced compared to the PMCAO plus saline control."

We regret any inconvenience that this inaccuracy in Figure Two (Figure 1 here) and therein the figure legend, which could not be properly corrected at the proof stage, in the originally published manuscript might have caused.

\footnotetext{
* Correspondence: plantproteomics@gmail.com; shioda@med.showa-u.ac.jp ${ }^{2}$ Department of Anatomy I, School of Medicine, Showa University, 1-5-8 Hatanodai, Shinagawa, Tokyo 142-8555, Japan

${ }^{4}$ Graduate School of Life and Environmental Sciences, University of Tsukuba, Tsukuba 305-8572, Japan

Full list of author information is available at the end of the article
} 


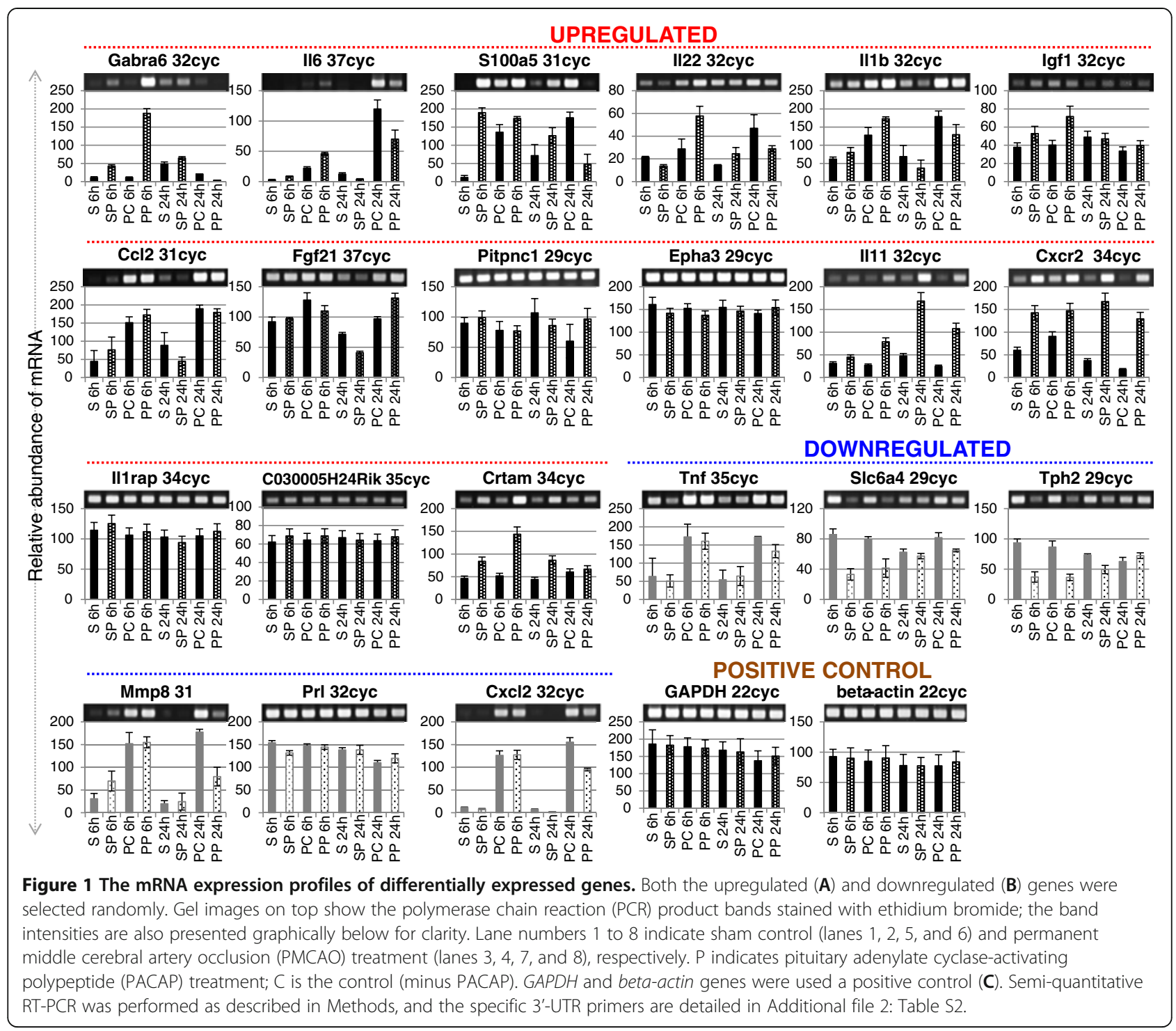

\section{Author details}

'Department of Forensic Medicine and Molecular Pathology, School of Medicine, Kyoto University, Kyoto 606-8315, Japan. ${ }^{2}$ Department of Anatomy I, School of Medicine, Showa University, 1-5-8 Hatanodai, Shinagawa, Tokyo 142-8555, Japan. ${ }^{3}$ Department of Center for Biotechnology, Showa University, 1-5-8 Hatanodai, Shinagawa, Tokyo 142-8555, Japan. ${ }^{4}$ Graduate School of Life and Environmental Sciences, University of Tsukuba, Tsukuba 305-8572, Japan.

Received: 31 January 2013 Accepted: 31 January 2013

Published: 31 January 2013

\section{References}

1. Hori M, Nakamachi T, Rakwal R, Shibato J, Ogawa T, Aiuchi T, Tsuruyama T, Tamaki K, Shioda S: Transcriptomics and proteomics analyses of the PACAP38 influenced ischemic brain in permanent middle cerebral artery occlusion model mice. J Neuroinflammation 2012, 9:256.

\section{doi:10.1186/1742-2094-10-18}

Cite this article as: Hori et al:: Correction: Transcriptomics and proteomics analyses of the PACAP38 influenced ischemic brain in permanent middle cerebral artery occlusion model mice. Journal of Neuroinflammation 2013 10:18.

Submit your next manuscript to BioMed Central and take full advantage of:

- Convenient online submission

- Thorough peer review

- No space constraints or color figure charges

- Immediate publication on acceptance

- Inclusion in PubMed, CAS, Scopus and Google Scholar

- Research which is freely available for redistribution 